\title{
Etiek in die nuwe Suid-Afrika
}

I W C van Wyk

Hervormde Teologiese Opleiding

Tydelik-deeltydse dosent: Departement Dogmatiek en Christelike Etiek (Afd A)

Universiteit van Pretoria

\begin{abstract}
Ethics in the new South Africa

This paper was read at a symposium where the calling of the church in the 'New South Africa' was discussed by delegates of twe churches, the Nederduitsch Hervormde Kerk van Afrika and the Hervormde Kerk in Suidelike Afrika. The 'New South Africa' will oblige the NHKA van Afrika as well as the HKSA to develop a new orientation in ethical matters. The churches will have to concentrate on a wider range of ethical problems that were not in focus in the 'Old South Africa'. The new situation is going to force White and Black Christians to work together harmo-niously. Suggestions are made as to how the churches can concentrate more effectively on ethical questions.
\end{abstract}

\section{DIE 'NUWE SUID-AFRIKA'}

Wanneer ons oor etiek en etiekbeoefening in die 'nuwe Suid-Afrika' wil handel, sal ons vir onsself eers duidelikheid moet kry oor wat met die 'nuwe Suid-Afrika' bedoel word. Hierdie term het in die laaste jare 'n algemeen gebruiklike uitdrukking geword waaraan verskillende betekenisinhoude gegee word. Om hierdie rebe wil ek probeer omskryf wat met die term binne die verband van die simposium* bedoel word. Die uitdrukking 'nuwe Suid-Afrika' verwys hier na die omstandighede waarbinne etiek beoefen moet word. Hierdie omstandighede is ingebed in die magsinstellings, invloedsfere en staatkundige strukture wat in 'n groot mate minstens die kerk se benadering tot etiekbeoefening beinvloed. Om goed te begryp wat 'nuut' in ons land se omstandighede is, behoort ons eers na die omstandighede van die verlede te kyk.

* Lesing gehou tydens 'n simposium van die Nederduitsch Hervormde Kerk van Afrika en die Hervormde Kerk in Suidelik Afrika oor die roeping van die kerk in die 'nuwe Suid-Afrika' op 28 Oktober 1994. 


\subsection{Etiekbeoefening in die 'ou Suid-Afrika'}

Die politieke mag was oor die laaste aantal dekades in 'n groot mate in die hande van blanke Calvinistiese Afrikaners. Die finale besluite oor morele sake is deur die kabinet geneem. Die kabinet is in sy besluitnemingsprosesse deur veral die drie Afrikaanse Susterkerke begelei. In talle gevalle is voorstelle en aandrange van hierdie kerke spoedig in wetgewing omskep. Belangegroepe soos ander kerke en godsdienste, ekumeniese bewegings, swart politieke bewegings, vakbonde en handelsorganisasies was duidelik in 'n groot mate uit die besluitnemingsprosesse uitgesluit. Wette oor morele sake is dus op 'n outoritêre wyse deur 'n klein minderheidsgroepie gemaak. Etiekbeoefening binne die drie Afrikaanse Susterkerke was daarom ook in 'n groot mate op die skep van wetgewing afgestem. Hierdie situasie het dramaties verander.

\subsection{Etiekbeoefening in die 'nuwe Suid-Afrika'}

In die 'nuwe Suid-Afrika' is die politieke mag in 'n groot mate in die hande van swartmense waarvan sommige Christene, ander tradisionaliste en ander weer kommuniste is. Daarby oefen die Indiërgemeenskap, van wie die meeste Moslems en Hindoes is, ook geweldige groot invloed op die regerende African National Congress uit. Wetgewing oor morele sake word deur verskillende 'demokratiese prosesse' voorafgegaan. Alle moontlike belangegroepe - vanaf vakbonde tot subkulture - kan hierdie prosesse beïnvloed. Ook die ander godsdienste gaan in die 'nuwe Suid-Afrika' invloed uitoefen op die voorbereiding van wetgewing oor morele sake. Binne hierdie prosesse sal die Suid-Afrikaanse Raad van .Kerke waarskynlik nog 'n invloedryke bydrae kan lewer. Van die drie Afrikaanse Susterkerke sal waarskynlik slegs die Nederduitse Gereformeerde Kerk, en dan slegs in 'n mindere mate, invloed op hierdie prosesse kan uitoefen.

'n Ander nuwigheid is dat wetgewing oor morele sake nie meer net deur die filosofiese en godsdienstige oortuigings van mense bepaal gaan word nie, maar ook (en in sommige gevalle soos die wenslikheid al dan nie van die doodstraf, beslissend) deur die handves van fundamentele regte. Nie die moraal nie, maar die reg gaan in verskillende vraagstukke die deurslag gee.

\section{DIE VERANDERDE EN VERANDERENDE OMGEWING WAARBINNE ETIEK BEOEFEN MOET WORD}

Die 'nuwe Suid-Afrika' het alreeds (en is steeds besig om al meer) 'n omgewing te skep waarbinne etiek op 'n ongewone wyse deur die Nederduitsch Hervormde Kerk beoefen sal moet word. Die veranderinge wat alreeds plaasgevind het, is minstens die volgende: 
* Die Calviniste, veral Afrikaanse Calviniste, word nie meer deur die staat bevoorreg nie.

* Die kerke geniet nie meer die onvoorwaardelike steun van 'n 'Christelike owerheid' nie.

* Die sogenaamde swart kerke - en veral dié wat lid van die Suid-Afrikaanse Raad van Kerke is - is in ' $n$ baie beter en sterker bedingingsposisie as die tradisionele wit kerke wat nie deel van die Suid-Afrikaande Raad van Kerke is nie.

* Die Tradisionele Afrika Godsdienste is besig om weer groot veld te wen.

* Ideologieë soos die Engelse liberalisme het 'n magtige invloed wat hulle uitoefen op die openbare debat oor morele sake.

* Wetgewing oor morele en maatskaplike sake kom op 'n totaal ander wyse tot stand as in die verlede. Die minister en die drie Afrikaanse Kerke formuleer eenvoudig nie meer wetgewing nie. Verskillende 'demokratiese prosesse' is vandag die voorlopers vir wetgewing. Enige belangegroep kan vandag die proses na wetgewing beïnvloed en selfs manipuleer.

* Sekere praktyke wat in die oë van die kerk sonde is, soos homoseksualisme, word in die handves van fundamentele regte (hoofstuk 3.8.2) beskerm.

\section{DIE UITDAGING IN VERANDERDE OMSTANDIGHEDE.}

Daar behoort geen meningsverskil daaroor te bestaan dat minstens een doelwit van ons etiekbeoefening nie meer maklik haalbaar gaan wees nie. Ons as Afrikaanse Calviniste gaan nie meer so maklik ons oortuigings in wetgewing omskep kry nie. Ons sal ons menings nie meer op ander kan afdwing nie, ons sal hulle daarvan moet oortuig. Ons sal rekening moet hou met die kompetisie van ander tradisies, godsdienste en filosofieë:

Ten spyte daarvan dat die omstandighede waarbinne etiek beoefen word, verander het, het die uitdaging self nie verander nie. Die uitdaging bly onder andere die volgende:

* om vanuit die perspektief van jou eie tradisie antwoorde op die etiese vraagstukke van vandag te gee. 
* om die waarheid en die sin van jou perspektief aan andere te verduidelik en te verkoop'.

Waarna ons dus na my mening in die 'nuwe Suid-Afrika' moet trag, is die volgende: om Reformatoriese etiek wat ekumenies kommunikeerbaar en bo-konfessioneel bruikbaar is, te beoefen.

\section{AKTUELE TEMAS WAARAAN AANDAG GEGEE SAL MOET WORD}

In die 'nuwe Suid-Afrika' is daar 'n magdom van etiese temas waaraan die etiek aandag sal moet gee. Hierdie sake gaan in 'n groot mate die stabiliteit, vrede en voorspoed van hierdie land bepaal. Die voorbeelde wat genoem word, maak hoegenaamd nie op volledigheid aanspraak nie. Hulle is na my mening slegs die belangrikste sake waaraan aandag gegee sal moet word.

\subsection{Tradisionele vraagstukke in die Christelike etiek}

* Lewe en dood

- Die doodstraf

* Interpersoonlike verhoudinge

- geweld, wraak

* Gesins- en huwelikslewe

— oorbevolking, aborsie, gesinsbeplanning, kindermishandeling

* Die verhouding kerk - staat

- Die verpligting van die owerhede teenoor die Christelike godsdiens.

- Protes, weerstand en opstand

* Eiendom en besit

- Die behuisingsprobleem.

\subsection{Unieke probleme in die post-apartheid era}

* Regstellende aksie

- Arbeidsgeregtigheid, omgekeerde rassisme

* Die skuld aan apartheid

- Skuldbelydenis, vergewing, versoening

* Onderwys

- Ongeletterdheid, voorsiening van onderwys vir almal, volkseie en raseie onderrig. 


\subsection{Vraagstukke wat die swart wêreld intens raak \\ * Bevryding \\ - Vroue-emansipasie teenoor die tradisionele reg.}

\subsection{Vraagstukke wat die wit wêreld intens raak}

* Arbeid

— Hardwerkendheid/eie inisiatief teenoor diskriminasie op grond van wit vel.

\section{DIE PROBLEMATIEK VAN DIE SAAMKOMS VAN TWEE KULTURE}

In die 'nuwe Suid-Afrika' gaan twee kulture (breedweg die Afrika- en Europese kulture genoem) wat in 'n groot mate in die verlede apart ontwikkel het, gedwing word om mekaar te ontmoet en saam verder te ontwikkel. Hierdie ontmoeting en uitdaging om saam te werk en saam te ontplooi, kan besondere probleme oplewer. Een van die probleme is om mekaar se handelinge en motiewe vir hierdie handelinge te verstaan, aangesien daar groot kulturele verskille bestaan. Sekerlik is dit so dat duisende en dalk miljoene swartmense al in só ' $n$ mate verwesters het, dat onderlinge begrip al baie makliker geword het. Tog is dit ook só dat miljoene swartmense nog nie verwesters het nie en nie wil verwesters nie en doelbewus wegbeweeg van die Westerse of Europese kultuur (König 1993:32)1. Die opspraakwekkende boekie van Attie van Niekerk (1993) bewys hierdie argument. In 'n baie groot mate word Afrika-mense se gedrag deur hulle tradisionele Afrika-godsdienstigheid bepaal. Dit is veral tussen laasgenoemde mense en die blanke Protestante waar groot misverstande verwag kan word. Die volgende etiese misverstande, probleme en konflikte kan tussen hierdie twee groepe verwag word:

\subsection{Norme teenoor die voordeel vir die gemeenskap}

Blanke Calviniste dink en handel volgens norme, beginsels en riglyne wat gevorm word deur die Bybel, belydenisskrifte, teologie en kerklike leefwyse. Hierdie groep openbaar dus 'n morele verpligting teenoor etiese riglyne wat in talle opsigte met hulle eie natuurlike drifte, begeertes en behoeftes in stryd is. Daar word ' $n$ absolute gehoorsaamheid aan hierdie norme, beginsels en riglyne verwag. Private en gemeenskapsbelange kan nooit as belangriker geag word nie.

In die 'etiek' van die tradisionele Afrika-godsdienste staan sake anders. Hier is dit nie 'n norm, beginsel of riglyn wat die primaat in morele gedrag is nie, maar die belang van die gemeenskap. Die 'lewensprinsiep' is vir die Afrikaan baie belangriker as die 'liefdesprinsiep' (Hasenhüttl 1991:37). Die rede daarvoor is in die feit te vinde dat Afrika aan 'n sogenaamde 'lewenskragfilosofie' (Hasenhüttl 1991:31, König 1993: 37-39) geöriënteer is. Om te lewe, beteken om aan die lewenskrag van die wêreld deel 
te neem. God is die naaste aan hierdie lewenskrag. Na God volg in 'n hiërargiese volgorde die geeste, die voorvaders, die koning, die kapteins, die ouers en heel laaste die kinders. Hierdie lewenskrag moet ten alle koste bewaar word. Alles wat die lewe die volheid van lewe - in 'n bepaalde gemeenskap bedreig, moet uitgeskakel word. Om hierdie rede moet een baba van 'n tweeling na geboorte doodgemaak word, aangesien die gemeenskap nie twee babas aan die lewe kan hou, sonder dat hulle die lewenskrag van die gemeenskap bedreig nie. Twee babas gebruik tweemaal soveel melk as een baba. Die minder beskikbare melk as gevolg van te veel babas bedreig die lewenskrag van 'n gemeenskap (Van Tonder 1987:8). Die norm 'jy mag nie doodmaak nie' is dus van minder belang as die 'lewensnorm'.

Daar kan ook na 'n tweede voorbeeld verwys word. In die blanke Calvinistiese wêreld word daar groot klem op die verwagting geplaas dat mense die waarheid sal praat. Waarheid word dan verstaan as die weergawe van gebeure en woorde van ander wat so na as moontlik feitelik korrek moet wees. In Afrika is 'waarheid' nie die weergawe van objektiewe gegewendhede nie, maar die permanente poging om jou gespreksgenoot nie te beledig en ongemaklik te laat voel nie. Die waarheid is aan die gemeenskapservaring ondergeskik. Selfs 'n leuen kan vertel word, solank die goedgesindheid van die gespreksgenoot behou kan word (Hasenhüttl 1991:37-38). 'Waarheid' is vir die Afrikaan ook nie konstant nie. Waarheid kan die een dag dit wees en die ander dag dat. Dít is ook nie snaaks nie, aangesien argumentasie en debat nie oor feite en waarhede gaan nie, maar om die manipulering van die onsigbare magte wat die lewe beheers. 'Waarheid' is nie van soveel belang nie - mag wel (Van Niekerk 1992: 26, 34-36). Wat die lewe bevorder - my eie en dié van ander aan wie ek met solidariteit verbind is - is goed. Selfs leuens (vanuit 'n blanke perspektief) kan in hierdie verband positief benut word. Ons het dus hier te make met 'n 'seinsmäßig Guten' waaruit die 'moralisch Gutes' afgelei word (Hasenhüttl 1991:38). Die homo Africanus sal dus eerder aan die waarheid te kort doen as om die groep te na te kom, ten spyte van Eksodus 23:2 (Van Wyk 1993:91).

Hierdie verskil in morele grondoriëntering móét tot misverstande, onbegrip en konflik aanleiding gee. Wanneer 'n blanke verpleegster sien hoe een van 'n tweeling versmoor word, sal sy dit as moord beskou terwyl die swart verpleegster dit as 'n goeie morele daad sal beoordeel. Wanneer groepe oor 'n bepaalde saak onderhandel, maar daar bestaan geen gemeenskaplike siening oor waarheid nie, is die vraag: hoe is konsensus hoegenaamd moontlik?

\subsection{Individualisme teenoor kollektivisme.}

Antropologies bestaan daar 'n geweldige groot verskil tussen swartmense en witmense. Die verskil kom daarop neer dat witmense meer individualisties is en swartmense oor 
die algemeen weer kollektiwisties (Thorpe 1993:38-48; König 1993:32-42; Van Wyk 1993:87-91; Van Niekerk 1993:29, 50; Mbiti 1985:100-109). 'Well-being', geluk, harmonie, heil het in Afrika met eenheid en solidariteit te make (Thorpe 1993:110-113; Van Wyk 1993:87-88). Die groep is daarom altyd belangriker as die indiwidu. 'n Mens is alleenlik mens deur ander mense, sê die swartman. Lewe is daarom vir hom lewe-in-partisipasie (Van Wyk 1993:89). Hierdie gemeenskaps- en solidariteitsdenke is só sterk dat selfs sonde primêr sonde teen die gemeenskap (en veral die voorvadergemeenskap), en nie sonde teen God is nie (Van Wyk 1993:89). Banana (1981:97) het die konsekwensie vir die Christelike etiek waarskynlik die beste opgesom toe hy gesê het: '(The church) should discard the individualistic ethic of Western culture and emphasize the collectivism found in African culture. This ethic is the fountain of hope for all future generations. It will be Africa's contribution to mankind'.

Ten spyte van talle positiewe dinge wat uit hierdie lewensvisie na vore kom, soos die wedersydse sorg en hulp aan mekaar, is daar aspekte waarmee Europeërs moeilik mee sal kan saamlewe. Die strydkreet op die universiteitskampusse 'pass one, pass all' (Van Niekerk 1993:29) is een van die dinge waarmee blankes nie vrede sal maak nie. 'n Ander is die intolle-ransie en selfs die moord op presteerders in 'n gemeenskap (Van Niekerk 1993:46,59). Individue mag nie bokant hulle omstandighede uitstyg nie. Doen hulle dit, word hulie van 'n gebrek aan solidariteit beskuldig. Hulle kom onder verdenking dat hulle bose magte het wat hulle help, en kan daarom doodgemaak word ${ }^{3}$. Om jou plek in 'n samelewing te ken en dár te bly vir die res van jou lewe, druis in teen die prestasiedenke van die witman (König 1993:35).

\subsection{Die bose, skuld en morele praktyke.}

Binne alle godsdienste word daar een of ander samehang tussen katastrofes en menslike skuld gekonstateer. In die tradisionele Afrika-godsdienste (Hasenhüttl 1991:38-41; Hammond-Tooke 1993:169-183; Ray 1976:150-152; Mbiti 1985:204-215) word daar drie denkmodelle gebruik om hierdie samehang te verduidelik. Twee van hierdie modelle het belangrike konsekwensies vir die Afrika-'etiek'. In die eerste model word katastrofes teruggevoer na gebrekkige en onvoldoende offers aan die voorvaders. Veral natuurkatastrofes, soos droogte, word binne hierdie model verklaar. Die oplossing vir hierdie tipe probleme lê doodgewoon in die konsekwente toepassing van die offerrites (Parrinder 1981:58-61). In die tweede model word daar 'n samehang tussen die straf van (die onbelangrike) God en 'n bose daad gekonstrueer. In Afrika bestaan daar altyd 'n direkte kousale samehang tussen natuurlike katastrofes (veral 'n dood wat deur weerlig veroorsaak is) en menslike skuld. Daar word geglo dat alle natuurlike katastrofes an menslike skuld of booswilligheid te wyte is. Selfs die 'natuurlike' dood van kinders en jongmense het sosiologiese oorsake. Volgens hierdie model kan katastroíes 
hulle oorprong nie in God hê nie, aangesien God die naaste aan die 'lewenskrag' is. Die dood, die negatiewe, kom daarom nie van God nie. Dit beteken egter nie dat God niks met die negatiewe te make het nie. Hy het wel daarmee te make en wel in dié sin dat God die sonde wat in 'n gemeenskap voorkom, straf. Die sondaar self word nie gestraf nie, maar ' $n$ ander persoon word vir die sonde van die sondaar gestraf. Die gemeenskap, en in die besonder die isangoma, het nou die verantwoordelikheid om die werklike sondaar uit te wys en te straf - meestal met die dood. Die derde model het met toordery en heksery te make. In Afrika word daar geglo dat ernstige siekte en dood ook met die bose werke van toordokters en hekse te make kan hê. Daar word geglo dat daar altyd booswillige mense in 'n gemeenskap is wat mense te na wil kom as gevolg van jaloesie en gemeenheid (Van Tonder 1987:8-9; Van Niekerk 1993:36; König 1993:38-39). Die groot probleem is dat enige iemand 'n toordokter of heks kan wees. Wanneer daar ' $n$ katastrofe plaasgevind het, soos 'n kind wat skielik doodgegaan het, moet hierdie persoon deur die waarsêer of isangoma uitgewys of geïdentifiseer word (Thorpe 1991:45). Wanneer die 'sondebok', gewoonlik 'n vrou wat van toordery of heksery verdink word, uitgewys is, moet sy deur die kinders doodgemaak word. Hierdie hantering van die teodiseeprobleem (Hammond-Tooke 1993:175-178) gee duidelik tot morele praktyke aanleiding wat hoegenaamd nie met die laat-Westerse Christendom en Europese geesteswêreld versoenbaar is nie. Skuldigbevindings sonder bewyse, doodsvonnisse sonder die moontlikheid van appèl en vonnisvoltrekking deur kinders op onskuldige mense is nie dinge waarmee 'n Europese Calvinis geïdentifiseer kan word nie.

\subsection{Voorvaderaanbidding en die etiek.}

Die aanbidding van voorvaders is ' $n$ fenomeen van die tradisionele godsdienste wat by feitlik al die volke en stamme van Afrika voorkom (Parrinder 1981:57-66). Die rede vir die aanbidding en verering van die voorvaders het in die eerste instansie met die Afrika-konsep van lewe te make. Die voorvaders is naas God, die naaste aan die "bron van die lewe'. Hulle wíl die lewe, skep lewe en wil sien dat lewe voortgaan. Lewe bestaan dus danksy die voorgeslagte. Wat mense is en wat hulle het, het hulle aan hulle voorgeslagte te danke. Hierdie afgestorwe voorvaders bestaan steeds voort. Hulle staan ook bekend as die 'lewendige dooies' (Mbiti 1985:75-91). Hulle wat nou baie ná aan die 'bron van die lewe is', wil nog steeds die lewe van hulle nakomelinge bestem, bepaal en ten goede beïnvloed. In die tweede instansie is 'God' in die tradisionele Afrika-godsdienste niks meer as 'n Deus otiosus, 'n God wat wel geskape het, maar niks verder met die skepping te make het nie ${ }^{4}$. Nie God nie, maar die voorvaders is dus vir die welwese van die stam verantwoordelik. Om hierdie redes is die stam aan 
die voorvaders groot eer en aanbidding verskuldig (Hammond-Tooke 1993:149-167). Die eerste belangrike daad wat aan hulle gedoen moet word, is om hulle behoorlik te begrawe. Gestorwenes wat nie 'n behoorlike begrafnis ontvang het nie, mag hulle goedgesindheid van die agtergeblewenes weerhou. Dit is juis hier by die begrafnisrites waar die weë tussen Europa en Afrika weer uitmekaargaan. Hier vind dinge plaas wat eties hoegenaamd nie aanvaarbaar kan wees vir mense wie se lewens deur Westerse sedewette bepaal word nie. By sommige stamme gebeur dit dat stamkapteins saam met verskeie gawes begrawe word. Hierdie gawes sluit metgeselle en wagters in. Mense (dikwels kinders) of hulle koppe word dan saam met die kaptein begrawe (Hasenhüttl 1991:43; Hammond-Tooke 1993:153; Van Tonder 1987:21; Parrinder 1981:62-63; Van Niekerk 1993:47). Dit is vir Eoropeërs eenvoudig ondenkbaar dat 'nasievorming' met mense wat rituele moorde goedpraat, moontlik is.

Daar kom nou alreeds vir ' $n$ lang tydperk optrede, deur veral swart jeugdiges voor wat vir die blanke gemeenskap onbegryplik en onaanvaarbaar is. Een van hierdie optredes is die vernietiging van eiendom soos skole en universiteite. Vir hierdie optrede gee Van Niekerk (1993:39) die volgende verklaring: Hy meen dat die swartman daarvan oortuig is dat die ou dinge aan die begin van 'n nuwe tydperk vernietig moet word, sodat 'n nuwe lewe begin kan word. 'n Ander gebruik, dat alles na die dood van ' $n$ hoofman of koning toelaatbaar is, is net so onverstaanbaar. Ons het aan die einde van die Lucas Mangope era iets soortgelyks ervaar. Vir hierdie optrede bestaan daar ook 'n verklaring. Almal kan ná die dood van 'n hoofman roof en plunider net soos hulle wil, aangesien die nuwe hoofman of koning alle skuld (diefstal ensovoorts) simbolies op homself neem om sodoende 'n nuwe sosiale orde te skep (Hasenhüttl 1991: 43). Hierdie denksisteem bly egter vir Calviniste totaal onbegryplik en onaanvaarbaar. Om af te breek wat met groot moeite en inspanning opgebou is, sal ons seker nooit kan begryp nie. Ek meen dat 'n ander en ewe waarskynlike verklaring aangebied kan word. Hierdie verklaring sentreer op die samehang tussen voorvaderaanbidding en die ekonomie. Die voorvaders word met die veronderstelling aanbid dat hulle die voorsieners van die lewensmiddele is. Die regte en genoegsame rituele praktyke verseker die voorsiening van die basiese lewensmiddele. Hierdie godsdienstige verstaan moet noodwendig ' $n$ invloed op arbeid, beplanning en die na waarde skat van arbeidsprestasies hê. Wanneer dit wat is en dit wat tot stand gebring is, alleenlik aan die voorvaders te danke is, dan kan maar afgebreek word aangesien daar weer voorsien sal word. Dit behoort bekend te wees dat blanke Calviniste die verhouding tussen godsdiens en ekonomie weer anders verstaan en daarom ander waarde aan arbeidsprestasies heg. Dit was die sosioloog Max Weber wat in 1919 met sy beroemde tese oor die 'binne-wêreldlike askese' daarop gewys het dat die Calvinisme tot 'n baie groot mate verantwoordelik was vir die ontwikkeling van die kapitalistiese sisteem en die 
daarmee gepaardgaande waarde van arbeidskonsensieusiteit (Weber 1979:344-348). Alhoewel daar nie in alle opsigte met Weber saamgestem kan word nie, bly dit 'n redelik aanvaarde stelling dat die Calvinisme ' $n$ besondere bydrae lewer tot arbeidsprestasies (vir 'n kritiese bespreking, kyk Küng 1994:661-664).

'n Laaste opmerking oor die samehang tussen voorvaderaanbidding en etiek moet gemaak word. In die tradisionele Afrika-godsdienste bemoei God Homself nie met die morele sy van mense se lewens nie. Dit is die voorvaders wat waghou oor die sosiale en morele orde, omdat die morele orde se oorsprong by hulle lê. Die ontwerpers van die morele orde is ook die bewakers daarvan. Wat egter van belang is, is dat die voorvaders nie die totale morele sfeer bewaak nie. Hulle het slegs belang by die morele verpligtinge wat mense teenoor die gemeenskap het. Die implikasie is dat ' $n$ moreel korrupte persoon voor die oë van die voorvaders kan floreer, aangesien hulle nie goeie dade beloon of slegte dade straf nie. Solank 'n persoon sy sosiale en kultiese verpligtinge nakom, kan hy eintlik maar doen wat hy wil, aangesien hierdie dimensie van menswees die voorvaders nie aangaan nie (Ray 1976:146-150). Teologies is die implikasie dat daar binne die tradisionele Afrika-godsdienste nie so iets soos 'n eindoordeel kan wees nie. Ten spyte daarvan dat feitlik al die swart stamme van Suider-Afrika aan 'n lewe na die dood glo, is dit bekend dat die tradisionele Afrika Godsdienste nie 'n eindoordeel ken nie. Tradisionele swartmense leef dus nie met die verwagting dat hulle na die dood op grond van hulle werke beloon gaan word nie. Net so leef hulle ook nie met die vrees dat hulle na die dood vir hulle bose dade gestraf gaan word nie (Hammond-Tooke 1993:149; König 1993:40; Mbiti 1985:161, 210). Hierdie leemte in die tradisionele Afrika-godsdiens skep na my mening 'n geweldige groot kloof tussen Europeër en Afrikaan. As Europeër is dit baie moeilik om in te sien hoe 'n gesamentlike kultuur geskep kan word wanneer sommige mense in hierdie land godsdienstig toegelaat word om op morele gebied eintlik maar te doen wat hulle wil.

Daar is natuurlik talle ander temas en voorbeelde van potensiële misverstande en konflikte tussen wit en swart wat genoem kan word. Hier is ongelukkig nie daarvoor plek nie. Belangstellendes kan gerus by Van Niekerk (1993), Hasenhüttl (1991) en Mbiti (1985) oor probleme soos die verskil in tydsbegrip lees.

Ek is daarvan bewus dat hier ' $n$ eensydige aanbieding van probleme is. Ek is daarvan bewus dat wat hier aangebied is, eensydig uit die oogpunt van 'n blanke Westerling kom. Dit is doelbewus ter wille van 'n baie noodsaaklike gesprek wat aan die gang moet kom, só aangebied. 


\section{DIE STATUS EN BELANGRIKHEID VAN ETIEK}

Daar kan geen twyfel daaromtrent bestaan dat etiese probleme tans die teologiese toneel oorheers nie. Sake soos die wettiging van prostitusie, dobbelary en aborsie is van die dringendste waaraan ' $n$ kerk in Suid-Afrika aandag moet gee. Gemeentepredikante sal daarvan kan getuig dat 'n groot deel van hulle tyd aan sake soos kindermishandeling, verkragting en armoede afgestaan word. Die tyd is ook verby dat sinodale vergaderings net suiwer dogmaties oor byvoorbeeld die sakramente kan praat. Die brandendste vraagstuk rondom die nagmaal is nie meer die vraag na die liggaamlike teenwoordigheid van Christus nie, maar die vraag of 'n homoseksueel verbied kan word om aan die nagmaalstafel aan te sit. Hiermee wil ek nie te kenne gee dat die etiese sake die dogmatiese vrae moet verdring en selfs vervang nie. Ek meen nog steeds dat die dogmatiek die primaat moet hê. Maar dan moet dogmatiek ook etiek wees, soos wat Karl Barth dit gestel het (KD 1/2,875-890). Die dogmatiek moet daarom die aandag aan etiek afstaan wat dit verdien. Paul Tillich (1962:13) het alreeds in 1919 die volgende stelling gemaak: 'es war die dogmatische Fragestellung, welche bislang die Kirche bewegte; von nun an wird es die ethische sein'. Niemand behoort dit te ontken dat hierdie voorspelling waar geword het nie. Die feit dat etiese vraagstukke ons lewens beheers, het die implikasie dat die kerk en die teologie baie meer aandag aan etiese vraagstukke sal moet afstaan. Wanneer daar gepleit word dat daar in die Nederduitsch Hervormde Kerk van Afrika en Hervormde Kerk in Suidelike Afrika die nodige aandag aan etiese sake gegee word, is dít nog nie 'n stappie in die rigting om van etiek 'Fundamentaltheologie' te maak soos wat Wilhelm Herrmann en Gerhard Ebeling dit bepleit het nie. Ook is daar geen behoefte om die vakgebied etiek in 'dogmatiekkritiek' te omskep soos wat Richard Rothe dit 'gedoen het nie (vir 'n volledige en diepgaande oorsig oor die verhouding tussen dogmatiek en etiek, kyk Birkner 1978:281-296; Honecker 1990:20-32). Al wat bepleit word, is dat daar indringend aandag aan die vrae van ons tyd gegee sal word.

\section{AANBEVELINGS.}

\subsection{Etiek aan die Universiteit van Pretoria.}

* Daar kan oorweging daaraan geskenk word om etiek tot 'n selfstandige departement uit te bou.

* Indien hierdie voorstel om finansiële redes nie haalbaar is nie, moet daar aan die volgende voorstelle oorweging geskenk word: 
- Die Bybelwetenskappe maak voorsiening daarvoor om meer aandag aan etiek af te staan.

- Die vakke Godsdienswetenskap en Kerkgeskiedenis kan ook daaraan dink om 'n bietjie aan etiek te raak.

- Ampsetiek en ander dringende etiese kwessies kry in die Departement Praktiese Teologie die nodige aandag.

\subsection{Etiek aan die Hervormde Teologiese Opleiding.}

* Die Hervormde Teologiese Opleiding kan die voorstelle wat ten opsigte van die Universiteit van Pretoria gedoen is, ook ter oorweging neem.

* Die kuratorium oorweeg dit om in samewerking met die dosent in etiek 'n jaarlikse kursus oor ampsetiek aan te bied.

\subsection{Die Raad vir Maatskaplike Sake}

* Die raad se werkwyse en samestelling word verander om die kerk in staat te stel om betyds gereelde getuienis oor etiese kwessies te laat hoor. Die volgende word aan die hand gedoen:

- Die raad funksioneer soos 'n deurlopende seminaar. Verskillende probleme word deur kleiner en groter groepe, oor 'n langer tydperk, stap vir stap bespreek.

- Die raad dien as ' $n$ 'dagbestuur'. Afhangende van temas onder bespreking, word persone gekoöpteer om aan die bespreking die nodige diepgang te gee nodig mag wees. Die bedoeling is om soveel kundigheid moontlik by hierdie raad te betrek.

\subsection{Die Hervormde Kerk in Suidelike Afrika en etiese kwessies}

* Die Hervormde Kerk in Suidelike Afrika ondersoek die wenslikheid en moontlikheid om iets soos 'n 'raad vir maatskaplike sake' in te stel.

* Die Hervormde Kerk in Suidelike Afrika gee op sy sinodesittings meer aandag aan etiese kwessies. 


\subsection{Tussen-kerklike samewerking.}

* Die Nederduitsch Hervormde Kerk en die Hervormde Kerk in Suidelike Afrika doen gesamentlik navorsing oor etiese sake.

- Die rade vir maatskaplike sake werk nóú met mekaar saam.

* Die Nederduitsch Hervormde Kerk en Hervormde Kerk in Suidelike Afrika lewer gesamentlike getuienis aan die owerhede oor eties-maatskaplike sake.

\subsection{Ekumeniese samewerking.}

* Albei kerke doen ondersoek na die moontlikhede om met ander kerke saam te werk op hierdie gebied.

\section{Endnote}

${ }^{1}$ Die tese wat talle Engelse soos Hammond-Tooke (1993:215-219) verdedig, dat Suid-Afrika al só verwesters het dat die swart tradisionele kultuur en godsdiens geen kans op invloed in die 'nuwe Suid-Afrika' het nie, word hiermee verwerp.

2 Die totaal onbegryplike is dat dit tog in Venda geduld word dat sakemanne toegelaat word om rituele moorde te pleeg om daardeur vir hulle ekonomiese voorspoed te verseker. Só word dit ook geduld dat geleerde mense soos onderwysers se brein uitgeslag word, om vir die moordenaars tot voordeel te wees (Van Niekerk 1993:52-53)!

${ }^{3}$ Ek is daarvan bewus dat talle geleerdes soos Thorpe (1993:109) in die jongste tyd hierdie stelling betwis. Oorweldigende getuienisse bevestig egter hierdie stelling.

\section{Literatuurverwysings}

Banana, C S 1981. The gospel according to the Ghetto. Gweru: Mambo.

Barth, K 1960. Die kirchliche Dogmatik, Band 1/2. 5. Aufl. Zollikon: Evangelischer Verlag.

Birkner, H J 1978. Das Verhältnis von Dogmatik und Ethik, in Handbuch der christlichen Ethik, Band 1. 281-296. Freiburg: Herder.

Hammond-Tooke, D 1993. The roots of Black South Africa. Johannesburg: Jonathan Ball.

Hasenhüttl, G 1991. Schwarz bin ich und schön: Der theologische Aufbruch Schwarzafrikas. Darmstadt: Wissenschaftliche Buchgesellschaft.

Honecker, M 1990. Einführung in die theologische Ethik: Grundlagen und Grundbegriffe. Berlin: De Gruyter.

König, A 1993. Menslike mense: Gelowig nagedink, deel 5: Oor die mens en die sonde in die praktyk. Halfway House: Orion. 
Küng, H 1994. Das Christentum: Wesen und Geschichte. München: Piper.

Mbiti, J [1969] 1985. African religions and philosophy. 11th ed. London: Heinemann.

Parrinder, E G [1954] 1981. African traditional religion. 3rd ed. London: Sheldon.

Ray, B 1976. African Religions: Symbol, ritual, and community. New Jersey: Prentice-Hall.

Thorpe, S A 1991. African traditional religions. Pretoria: UNISA.

Tillich, P 1962. Der Sozialismus als Kirchenfrage, in Gesammelte Werke, Band II: Christentum und soziale Gestaltung. Hrsg v R Albrecht. Stuttgart.

Van Niekerk, A [1992] 1993. Sáám in Afrika. 3e Druk. Kaapstad: Tafelberg.

Van Tonder, C B 1987. Sosio-etniese danse van die Venda-vrou. Pretoria: HAUM.

Van Wyk, J H 1993. Homo Dei: 'n Prinsipiële besinning oor enkele mensbeskouings, waaronder dié van Calvyn. Potchefstroom: In die Skriflig. (Suppl 1.)

Weber, M [1919] 1979. Die protestantischen Sekten und der Geist des Kapitalismus in, Die protestantische Ethik, Band 1: Eine Aufsatzsammlung. 5. Aufl. Hrsg von J Winckelmann. Gütersloh: Mohn. (GTB 53.) 